\title{
Infectious agents is a risk factor for myxomatous mitral valve degeneration: $A$ case control study
}

\author{
Marcos Gradim Tiveron ${ }^{*}$, Pablo Maria Alberto Pomerantzeff ${ }^{2}$, Maria de Lourdes Higuchi ${ }^{2}$, Marcia Martins Reis ${ }^{2}$, \\ Jaqueline de Jesus Pereira², Joyce Tieko Kawakami², Renata Nishiyama Ikegami², \\ Carlos Manuel de Almeida Brandao ${ }^{2}$ and Fabio Biscegli Jatene ${ }^{2}$
}

\begin{abstract}
Background: The etiology of myxomatous mitral valve degeneration (MVD) is not fully understood and may depend on time or environmental factors for which the interaction of infectious agents has not been documented. The purpose of the study is to analyze the effect of Mycoplasma pneumoniae (Mp), Chlamydophila pneumoniae (Cp) and Borrelia burgdorferi $(\mathrm{Bb})$ on myxomatous mitral valve degeneration pathogenesis and establish whether increased in inflammation and collagen degradation in myxomatous mitral valve degeneration etiopathogenesis.

Methods: An immunohistochemical test was performed to detect the inflammatory cells (CD20, CD45, CD68) and $\mathrm{Mp}, \mathrm{Bb}$ and MMP9 antigens in two groups. The in situ hybridization was performed to detect Chlamydophila pneumoniae and the bacteria study was performed using transmission electron microscopy. Group $1(n=20)$, surgical specimen composed by myxomatous mitral valve degeneration, and group $2(n=20)$, autopsy specimen composed by normal mitral valve. The data were analyzed using SigmaStat version 20 (SPSS Inc., Chicago, IL, USA). The groups were compared using Student's t test, Mann-Whitney test. A correlation analysis was performed using Spearman's correlation test. $P$ values lower than 0.05 were considered statistically significant.
\end{abstract}

Results: By immunohistochemistry, there was a higher inflammatory cells/mm2 for CD20 and CD45 in group 1, and CD68 in group 2. Higher number of $\mathrm{Mp}$ and $\mathrm{Cp}$ antigens was observed in group 1 and more $\mathrm{Bb}$ antigens was detected in group 2. The group 1 exhibited a positive correlation between the Bb and MVD percentage, between CD45 and Mp, and between MMP9 with Mp. These correlations were not observed in the group 2. Electron microscopy revealed the presence of structures compatible with microorganisms that feature Borrelia and Mycoplasma characteristics.

Conclusions: The presence of infectious agents, inflammatory cells and collagenases in mitral valves appear to contribute to the pathogenesis of MVD. Mycoplasma pneumoniae was strongly related with myxomatous mitral valve degeneration. Despite of low percentage of Borrelia burgdorferi in MD group, this agent was correlated with myxomatous degeneration and this may occour due synergistic actions between these infectious agents likely contribute to collagen degradation.

Keywords: Mitral valve, Myxomatous degeneration, Borrelia burgdorferi, Mycoplasma pneumoniae, Chlamydophila pneumoniae, Metalloproteinases, Inflammatory markers

\footnotetext{
* Correspondence: mgtiveron@yahoo.com.br

${ }^{1}$ Program in Thoracic and Cardiovascular Surgery, Medical School, University

of Sao Paulo, Av. Dr. Enéas de Carvalho Aguiar, 44, Sao Paulo 05403-900, Sao

Paulo, Brazil

Full list of author information is available at the end of the article
}

\section{Ciomed Central}

(c) The Author(s). 2017 Open Access This article is distributed under the terms of the Creative Commons Attribution 4.0 International License (http://creativecommons.org/licenses/by/4.0/), which permits unrestricted use, distribution, and reproduction in any medium, provided you give appropriate credit to the original author(s) and the source, provide a link to the Creative Commons license, and indicate if changes were made. The Creative Commons Public Domain Dedication waiver (http://creativecommons.org/publicdomain/zero/1.0/) applies to the data made available in this article, unless otherwise stated. 


\section{Background}

Myxomatous mitral valve degeneration (MVD) is the most common mitral valve disease in developed countries [1]. It occurs when the valve matrix is compromised due to an imbalance in the levels of acid mucopolysaccharides [2,3]. Mitral valve prolapse is initiated by MVD, which serves as an anatomical substrate affecting the valve matrix. The prevalence of this condition is estimated at $2-3 \%$ and affects 150 million people around the world [4].

The etiology of this valvopathy is not fully understood. Familial forms show autosomal dominant transmission with variable penetrance, which may depend on age or environmental factors [5, 6]. In addition, inflammatory cells, autonomic imbalances of valve nerve endings and the action of metalloproteinases on collagen degradation can contribute to and enhance the degeneration of the valve matrix [7-9]. However, new contributing factors in the etiology of myxomatous degeneration should be sought to better understand this disease. Such knowledge could help to decrease postoperative recurrence, which occurs in approximately $69.2 \%$ of valve repair cases after 20 years of follow-up and is connected with degenerative progression [10]. Among potential contributing environmental factors, the participation of infectious agents in MVD pathogenesis has not been described in the literature as a causative factor; nevertheless, they may contribute to increasing the level of valve inflammation and collagen degradation. The presence of symbiotic bacteria is associated with tissue injury, as previously shown in studies analyzing atheromatous plaques in which proliferating $\mathrm{Myco-}$ plasma pneumonia (Mp) and Chlamydophila pneumoniae (Cp) bacteria led to inflammation, collagen degradation and vulnerable plaque formation [11, 12]. Borrelia burgdorferi $(\mathrm{Bb})$ is a bacteria that causes Lyme disease and leads to cardiac manifestations in $4 \%$ to $10 \%$ of cases; it may co-infect with various bacteria, including Mycoplasma pneumoniae [13, 14].

Based on this association between bacteria and tissue injury, the aim of this study was to analyze the presence and involvement of infectious agents in the increased inflammation and collagen degradation associated with the etiopathogenesis of myxomatous mitral valve degeneration.

\section{Methods}

\section{Valves studied}

We analyzed 40 segments of mitral valve tissue, divided into 2 groups of 20 fragments each. Group 1 (myxomatous degeneration, MD) consisted of mitral valve fragments collected from patients undergoing replacement or mitral valve repair after mitral regurgitation with mitral valve prolapse (MVP). MVP is defined by the presence of a systolic murmur in the mitral focus by clinical examination, supplemented by a transthoracic echocardiogram showing bulging of one or both leaflets at least $2 \mathrm{~mm}$ apart on the mitral valve ring plane, regardless of its thickness. MVD was further confirmed by histopathology analysis. Group 2 (control, CO) included segments of the mitral valve posterior cusp without signs of MVD collected in a macroscopic examination of the valve during necropsy of cadaver patients.

The exclusion criteria for the MD group were other cardiovascular diseases with a surgical indication and valve reoperation; for the $\mathrm{CO}$ group, samples from patients with known congenital or acquired heart valve disease or with any macroscopic signs of MVP were excluded. Additional exclusion criteria for both groups were age of less than eighteen years old and the nonagreement of the patient or legal representative for participation in the study.

The 40 fragments were analyzed using the following techniques: immunohistochemistry to detect $\mathrm{Myco}$ plasma pneumoniae, Borrelia burgdorferi, inflammatory mediators and MMP9 antigens; in situ hybridization to detect Chlamydophila pneumoniae; and transmission electron microscopy to observe the infectious agents.

\section{Study design (Fig. 1)}

This was an observational, analytical, case-control study. For each specimen, measuring approximately $2 \times 2 \mathrm{~cm}^{2}$, we prepared slices of $5-\mu \mathrm{m}$ sections for histological analysis, immunohistochemistry and in situ hybridization (fixation in 10\% formalin), and transmission electron microscopy (3\% glutaraldehyde fixation). All the evaluations were performed at the Cardiac Pathology Laboratory in the Heart Institute of the Clinical Hospital of the Medical School of the University of Sao Paulo. The Bioethics Committee of the Clinical Hospital of Medical School of the University of Sao Paulo approved the study under the number 0029/04.

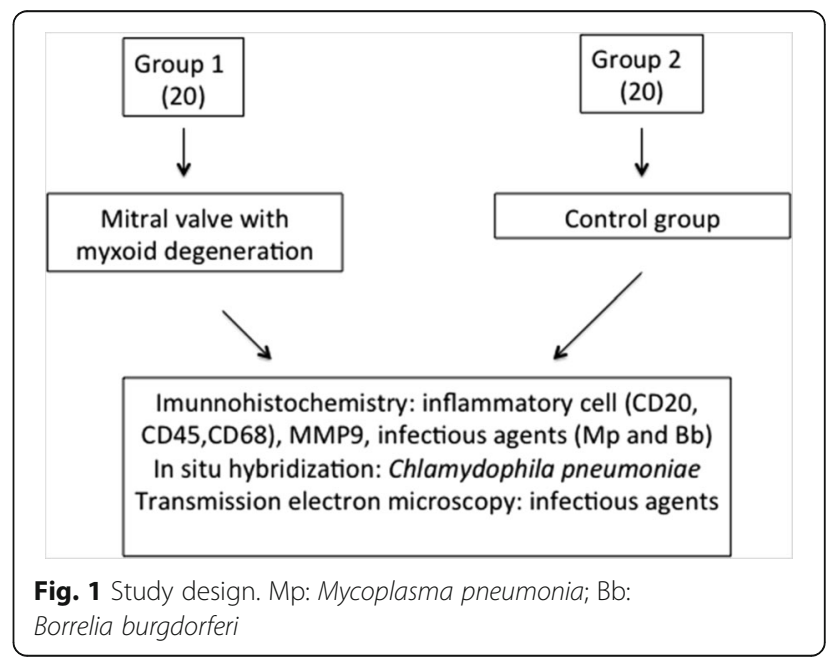




\section{Histology and immunohistochemistry (IHC)}

Five-micron serial sections of formalin-fixed, paraffinembedded tissue were cut and Movat-stained for immunohistochemical detection of antigens from microorganisms (Mycoplasma pneumonia and Borrelia burgdorferi), inflammatory cells (CD20, CD45 and CD68) and metalloproteinase. The tissue sections were deparaffinized in xylene, and antigen retrieval was performed in $0.01 \mathrm{~mol}-\mathrm{g} / \mathrm{L}$ citrate buffer, $\mathrm{pH}$ 6.0, for $10 \mathrm{~min}$ in a microwave. The slides were allowed to stand for $20 \mathrm{~min}$ at room temperature. To block endogenous peroxidase, the tissue sections were saturated with $6 \%$ hydrogen peroxide for $8 \mathrm{~min}$, followed by avidinbiotin blocking for $20 \mathrm{~min}$, incubation with a protein block for $30 \mathrm{~min}$ (Dako, Carpinteria, CA, USA), and then with primary antibodies against Mycoplasma pneumoniae (1:100; rabbit clone 10MR54; Fitzgerald International Inc., Concord, MA, USA), Borrelia burgdorferi (1:300; rabbit clone ab34970, ABCAM), MMP-9 (1:3200; rabbit clone RB1539P; Neo Markers Inc., Fremont, CA, USA), CD20 (1:1000; clone L26 M0755; Dako, Carpinteria, CA, USA), and CD45 (1:125; clone VCHL M0742 Dako, CA, California, USA) overnight. The reaction was visualized using a 3,30-diaminobenzidine tetrahydrochloride solution. The positive controls were aneurysm sections for Mycoplasma pneumoniae and MMP9, positive myocardium for Borrelia burgdorferi and amygdala for inflammatory cells.

\section{In situ hybridization (ISH)}

In situ hybridization was performed to detect Cp DNA $(50 \mathrm{ng} / \mu \mathrm{l})$ using the probe ACAACGGCTAGAAATCAATTATAAGACTGAAGTTGAGCATATTCGTGAG GGAGTGCAGATTTAGATCATGGTGTCATTGCCCA AGGTTAAAGTCTACGT. For cell permeabilization, we used Tris / 10 mM EDTA pH 9.0, endogenous peroxidase blocking with $6 \% \mathrm{H}_{2} \mathrm{O}_{2}$ and reduction of non-specific proteins with protein blocker (CAS Block - Invitrogen, MA, USA). The double-stranded DNA was denatured in an oven at $95 \pm 5{ }^{\circ} \mathrm{C}$, and in situ hybridization was performed at $60{ }^{\circ} \mathrm{C}$ for $19 \mathrm{~h}$ in an oven. The signal was amplified using the Genpoint kit (Dako, Carpinteria, CA, USA), and the reaction was visualized with 3,3-diaminobenzidine chromogen (Dako, Carpinteria, CA, USA). The probe was omitted for the negative control. Histological sections previously diagnosed as positive for Chlamydophila pneumoniae were used as positive controls for the reactions.

\section{Transmission electron microscopy (TEM)}

Mitral valve specimens were fixed in 3\% glutaraldehyde and postfixed in $1 \%$ osmium tetroxide solution. They were then washed in saline and kept until the next day in $0.5 \%$ uranyl acetate at $4{ }^{\circ} \mathrm{C}$. The fragments were dehydrated in an ascending series of ethanol and propylene oxide, followed by infiltration with a mixture of propylene oxide and araldite added to pure resin. The fragments were embedded in flexible molds containing silicone resin and polymerized for $48 \mathrm{~h}$ at $60{ }^{\circ} \mathrm{C}$. Semithin samples $(0.5 \mu \mathrm{m})$ were collected and stained with methylene blue with $1 \%$ borax and 1\% azure II. After selecting the best blocks, $70 \mathrm{~nm}$-thick sections were cut with an ultramicrotome and placed on 200 mesh copper screens. The screens were contrasted with uranyl acetate and 5\% lead citrate for examination under a transmission electron microscope (JEOL JEM-1010; JEOL Ltd., Akishima, Tokyo, Japan).

\section{Methods of analysis}

After immunohistochemical and in situ hybridization processing, the slides were scanned using a Scanscope CS System apparatus (Aperio Technologies, Inc., CA, USA) with a 20× Olympus UPlanSApo lens and $20 \times 1$ 0.75 specification. This device was coupled to a scanner that generated image files in svs format. The scanned images were analyzed using the Aperio ImageScope View Software program (Aperio Technologies, Inc., CA, USA). The Image Scope Software is a new technology that eliminates the use of an optical microscope. The samples were analyzed using this tool, and an algorithm for nuclear and membrane marking was selected. For inflammatory cell analysis (CD20, CD45, CD68), the total number of positive cells was divided by the area in $\mathrm{mm}^{2}$, and the rate is expressed as the total number of positive cells $/ \mathrm{mm}^{2}$. When the presence of a bacterial antigen and matrix metalloproteinase (MMP9) was detected, we counted the quantity of antigen signals in $\mu \mathrm{m}^{2}$ in an area $1 \mathrm{~mm}$ wide across the entire length of the valve.

\section{Statistical analysis}

The data were analyzed using SigmaStat version 20 (SPSS Inc., Chicago, IL, USA). The groups were compared using Student's t test for normally distributed variables; the results are expressed as the mean \pm standard deviation. The Mann-Whitney test was used for unpaired variables with asymmetrical distributions. Parametric data were expressed as the mean and standard deviation of the sample, and the independent groups were compared by Student's $t$ test and analysis of variance. Nonparametric data were represented by the median, lower quartile (25th percentile) and upper quartile (75th percentile). A correlation analysis of the asymmetrically distributed ordinal variables was performed using Spearman's correlation test. Spearman's correlation test was also performed in different groups to test whether the infectious agents exerted their effects in association with another agent, inflammatory cells, or MMP9. $P$ values lower than 0.05 were considered statistically significant. 


\section{Results}

\section{Studied population}

Forty mitral valve samples with MVD or a normal appearance were included. In group 1, 14 (70\%) patients were male, and $6(30 \%)$ were female. The mean age was $67.4 \pm 9.2$ years. The intraoperative findings during surgery on the mitral valve were prolapse in $9(45 \%)$ patients, ruptured chordae tendineae in 7 (35\%) patients and prolapse associated with chordal rupture in $4(20 \%)$ patients. According to the classification of Carpentier [15], the P2 segment was involved in 14 (70\%) patients, the A2 segment in $1(5 \%)$ patient, the A3 segment in 1 (5\%) patient, the P1 and P2 segments in 1 (5\%) patient, the P2 and P3 segments in 1 (5\%) patient, the A2 and A3 segments in $1(5 \%)$ patient, and the A2 and P2 segments in $1(5 \%)$ patient (Table 1). In group 2, 11 (55\%) patients were male, and 9 (45\%) were female. The mean age was $67.6 \pm 12.0$ years. The cause of death was acute myocardial infarction in 5 (25\%) cases, ischemic stroke in $4(20 \%)$ cases, acute respiratory failure due to pneumonia in $3(15 \%)$ cases, rupture of the ascending aorta during acute aortic dissection of the ascending aorta in 2 $(10 \%)$ cases, pulmonary embolism in $1(5 \%)$ case, hypertrophic cardiomyopathy in 1 (5\%) case, ischemic cardiomyopathy in $1(5 \%)$ case, acute pulmonary edema in 1

Table 1 Baseline characteristics of patients with myxomatous mitral valves

\begin{tabular}{|c|c|c|c|}
\hline Age, y & Gender & Clinical diagnosis / surgery & Cusp analyzed* \\
\hline 72 & M & $\mathrm{MD}+$ chordal rupture & P2 \\
\hline 51 & $\mathrm{~F}$ & $\mathrm{MD}+$ chordal rupture & A3 \\
\hline 73 & $\mathrm{~F}$ & $\mathrm{MD}+$ chordal rupture & $\mathrm{P} 2$ \\
\hline 72 & $\mathrm{~F}$ & $\mathrm{MD}+\mathrm{MVP}+$ chordal rupture & $\mathrm{P} 2$ \\
\hline 60 & $\mathrm{~F}$ & $\mathrm{MD}+\mathrm{MVP}+$ chordal rupture & $\mathrm{P} 2$ \\
\hline 59 & M & $\mathrm{MD}+\mathrm{MVP}$ & $P 1+P 2$ \\
\hline 72 & M & $\mathrm{MD}+\mathrm{MVP}+$ chordal rupture & $\mathrm{P} 2$ \\
\hline 73 & M & $\mathrm{MD}+$ chordal rupture & A2 \\
\hline 72 & M & $\mathrm{MD}+$ chordal rupture & $P 2+P 3$ \\
\hline 68 & M & $\mathrm{MD}+$ chordal rupture & $\mathrm{P} 2$ \\
\hline 68 & M & $\mathrm{MD}+\mathrm{MVP}$ & P2 \\
\hline 73 & M & $M D+M V P$ & P2 \\
\hline 79 & M & $\mathrm{MD}+\mathrm{MVP}$ & $\mathrm{P} 2+\mathrm{A} 2$ \\
\hline 56 & M & $\mathrm{MD}+\mathrm{MVP}$ & P2 \\
\hline 63 & $\mathrm{~F}$ & $\mathrm{MD}+\mathrm{MVP}$ & $A 2+A 3$ \\
\hline 69 & $\mathrm{~F}$ & $\mathrm{MD}+$ chordal rupture & P2 \\
\hline 44 & M & $M D+M V P$ & P2 \\
\hline 78 & M & $\mathrm{MD}+\mathrm{MVP}$ & P2 \\
\hline 69 & M & $\mathrm{MD}+\mathrm{MVP}$ & P2 \\
\hline 76 & M & $\mathrm{MD}+\mathrm{MVP}+$ chordal rupture & $\mathrm{P} 2$ \\
\hline
\end{tabular}

$M D$ myxomatous degeneration, MVP mitral valve prolapse.

*According to the Carpentier classification
(5\%) case, abdominal aortic aneurysm rupture in 1 (5\%) case, and heart failure in 1 (5\%) case (Table 2). The P2 segment was removed for analysis. None of the samples had signs of myxomatous degeneration in macroscopic analyses performed by two investigators, including the pathologist who performed the autopsies.

\section{Percentage of degenerated tissue}

The tissues were subjected to Movat staining to determine whether myxomatous degeneration was present. More degenerated tissue was observed in group 1, with a mean of $54.6 \% \pm 23.7 \%$ degenerated tissue, compared with group 2 , with $35.5 \% \pm 22.5 \%$ degenerated tissue ( $p=0.013$; $95 \%$ CI 4.3 to 33.9 ) (Fig. 2).

\section{Presence of inflammatory cells (Fig. 3)}

An analysis of $\mathrm{CD} 20^{+}$(B lymphocyte marker) and $\mathrm{CD} 45^{+}$ ( $\mathrm{T}$ lymphocyte marker) cells revealed significantly more positive cells $/ \mathrm{mm}^{2}$ in valves with myxomatous degeneration $\left(\mathrm{CD} 20^{+}\right.$cells: group 1 median $=17.8(6.7-27.9)$, group 2 median $=4.6(3.6-9.8), p=0.007 ; \mathrm{CD}^{+} 5^{+}$cells: group 1 median $=17.3(3.4-92.5)$, group 2 median $=2.8$ (1.4-10.1), $p=0.008$ ). An analysis of $\mathrm{CD}^{+} 8^{+}$cells (macrophage marker) revealed more positive cells $/ \mathrm{mm}^{2}$ in the control group (group 1 median $=38.7(26.6-81.8)$, group 2 median $=70(42.7-120.4), p=0.098)$ (Fig. 3a).

\section{Identification of bacteria by IHC, ISH and TEM (Fig. 4)}

The numbers of Mycoplasma pneumoniae, Chlamydophila pneumoniae and Borrelia burgdorferi bacterial antigens are expressed as $\mu \mathrm{m}^{2}$ antigens per $1 \mathrm{~mm}$ of analyzed valve segment length $\left(\mu \mathrm{m}^{2} \mathrm{Ag} / 1 \mathrm{~mm}\right)$. A significantly greater Mycoplasma pneumoniae antigen area was detected in the MD group. The median positive area in $\mu \mathrm{m}^{2} \mathrm{Ag} / 1 \mathrm{~mm}$ for Mycoplasma pneumoniae was 180,993 $(24,856-387,477)$ in group 1 (valves with myxomatous degeneration) versus $7970(2736-15,992)$ in group 2 (normal valves) $(p<0.001)$. Similarly, for Chlamydophila pneumoniae, group 1 presented a greater antigen area $($ median $=9905(4716-16,912)$ versus $5864(2382-8692)$ in group 2; $p=0.2$ ). By contrast, more Borrelia burgdorferi antigens were detected in the control group (group 1 median $=7596(3203-13,519)$, group 2 median $=10,584$ (7223-15,974); $p=0.14$ ) (Fig. 4a). Electron microscopy revealed the presence of structures compatible with microorganisms with Borrelia and Mycoplasma characteristics. The microorganisms identified in the MD group were smaller and thinner than the bacteria found in the control group.

MMP9 analysis and correlation test (Fig. 5)

The presence of MMP9 is expressed in $\mu \mathrm{m}^{2}$ of antigens per $1 \mathrm{~mm}$ valve segment length. We observed a significantly greater antigen area in the myxomatous 
Table 2 Baseline characteristics of the control patients

\begin{tabular}{|c|c|c|c|}
\hline Age, y & Gender & Cause of death & Post mortem interval, $\mathrm{h}$ \\
\hline 42 & M & Acute myocardial infarction & 6 \\
\hline 59 & M & Pulmonary thromboembolism & 7 \\
\hline 76 & M & Ischemic stroke & 3 \\
\hline 66 & M & Ischemic cardiomyopathy & 6 \\
\hline 82 & M & Ischemic stroke & 5 \\
\hline 63 & $\mathrm{~F}$ & Dissection of the ascending aorta & 9 \\
\hline 79 & $\mathrm{~F}$ & Dissection of the ascending aorta & 9 \\
\hline 73 & $\mathrm{~F}$ & Acute respiratory failure - Pneumonia & 10 \\
\hline 75 & M & Left Ventricular free wall rupture by acute myocardial infarction & 5 \\
\hline 54 & $\mathrm{~F}$ & Hypertrophic cardiomyopathy & 9 \\
\hline 74 & $\mathrm{~F}$ & Acute pulmonary edema & 9 \\
\hline 51 & M & Acute myocardial infarction & 10 \\
\hline 52 & M & Abdominal aortic aneurysm ruptured & 12 \\
\hline 80 & M & Acute respiratory failure - Pneumonia & 5 \\
\hline 60 & M & Acute myocardial infarction & 6 \\
\hline 61 & $\mathrm{~F}$ & Ischemic stroke & 6 \\
\hline 72 & $\mathrm{~F}$ & Ischemic stroke & 8 \\
\hline 84 & $\mathrm{~F}$ & Acute myocardial infarction & 5 \\
\hline 67 & M & Acute respiratory failure - Pneumonia & 14 \\
\hline 82 & $\mathrm{~F}$ & Heart failure & 9 \\
\hline
\end{tabular}

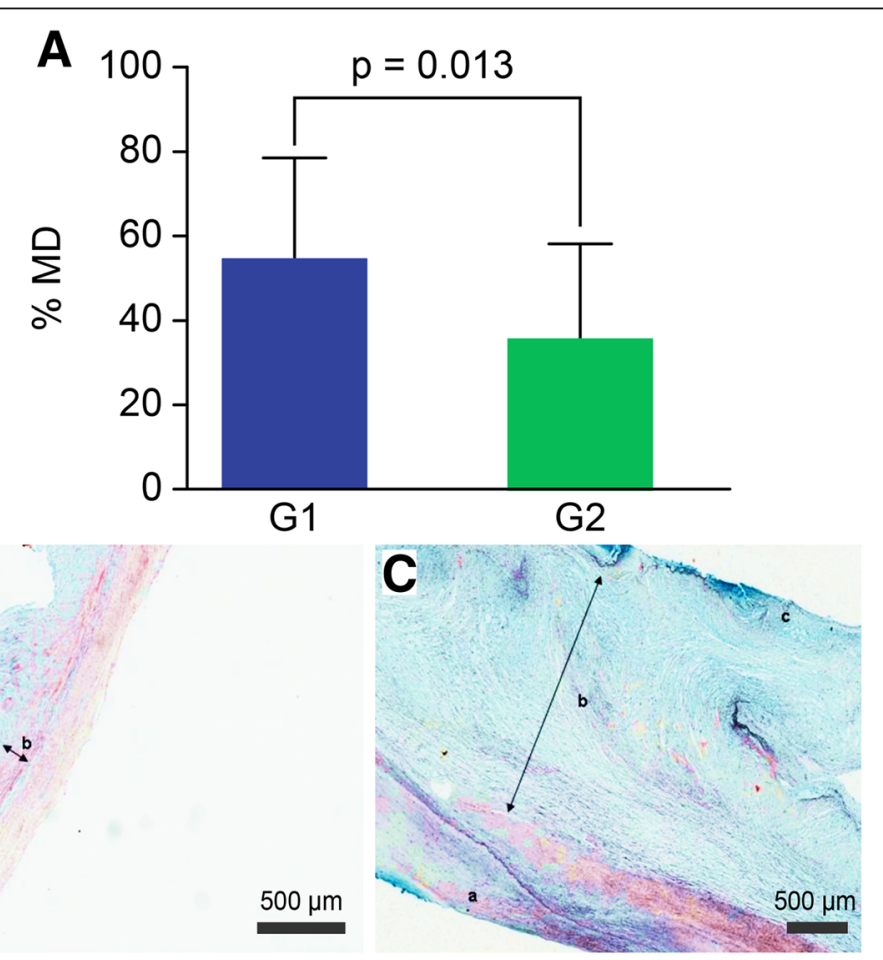

Fig. 2 Histological analysis of myxoid degeneration. a: analysis of myxomatous degeneration percentage (\% MD) in groups 1 and 2. b: Normal valve. c: Mitral valve with MVD. The valve with myxomatous degeneration shows diffuse and homogeneous thickening, distorted architecture, spongy layer expansion and proteoglycan accumulation, indicated by the bluish Movat staining (a: atrial layer, b: spongy layer, and c: fibrous layer). Bar $=500 \mu \mathrm{m}$. G1: group 1; G2: group 2; p: $p$ value 


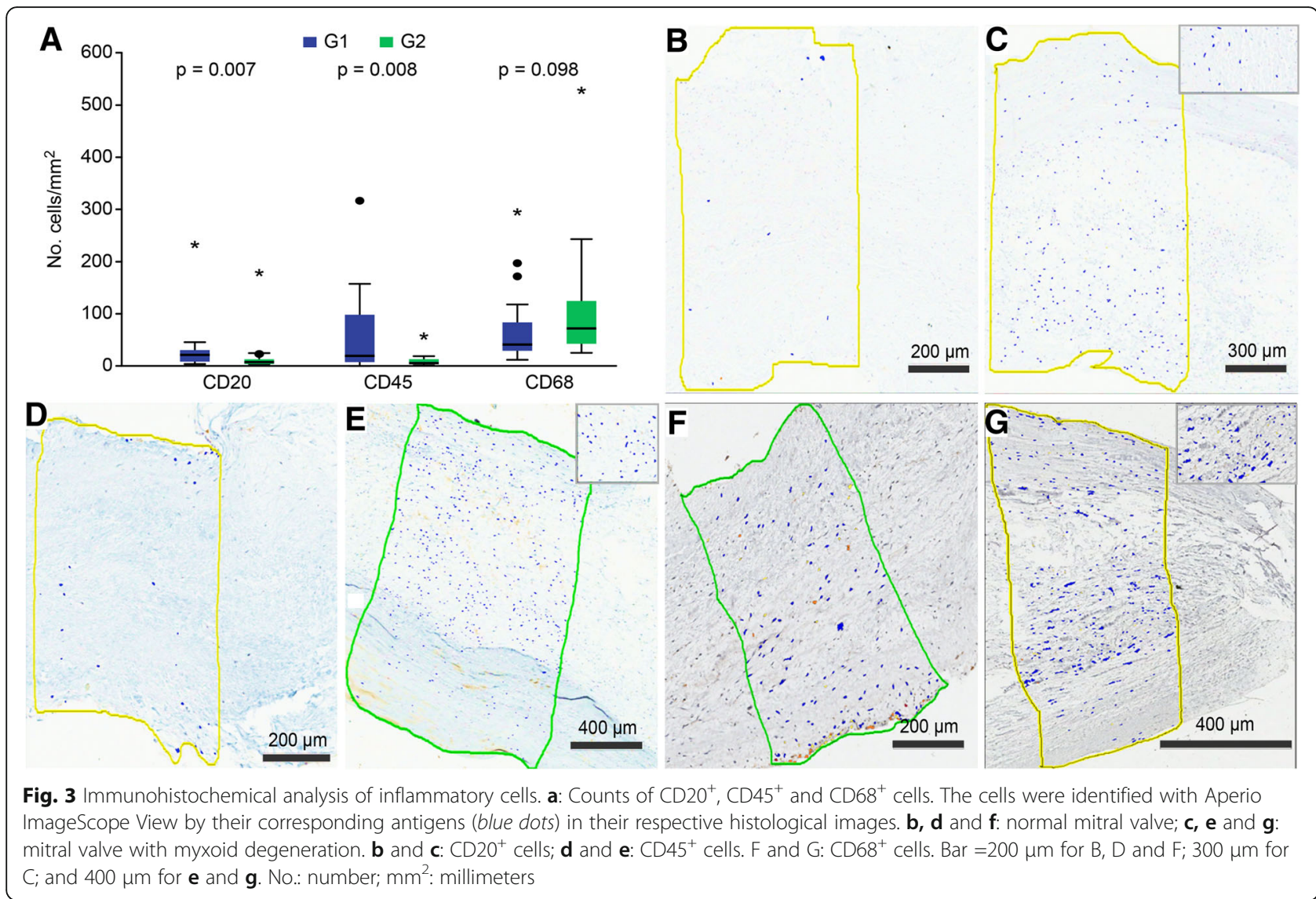

degeneration group $($ median $=389,844(214,459-679,711)$ versus $144,397(29,894-247,453)$ in group $2 ; p<0.001)$ (Fig. 5a).

The valves with myxomatous degeneration exhibited significant correlations between the quantity of bacterial antigens, inflammatory cells and MMP9: Borrelia burgdorferi was positively correlated with the MD percentage ( $r=0.52$ and $p=0.018$ ), and Mycoplasma pneumoniae was positively correlated with $\mathrm{CD} 45(r=0.51$ and $p=0.02)$ and MMP9 ( $r=0.45$ and $p=0.04)$. These correlations were absent in the control group (Table 3 ).

\section{Discussion}

To the best of our knowledge, this is the first report describing the presence of bacteria in the pathogenesis of myxomatous degeneration. Our results also show increased expression of CD20, CD45 and MMP9 in MVD.

In our work, we identified enhanced Mycoplasma pneumoniae and Chlamydophila pneumoniae antigens in mitral valves with MD compared with controls, with a median of $180,993(24,856$ to 387,477$)$ versus 7970 (2736 to 15,992$) \mu \mathrm{m}^{2} \mathrm{Ag} / 1 \mathrm{~mm}$ valve segment extension $(p<0.001)$ and $9905(4716-16,912) \times 5864(2382-8692)$ $\mu \mathrm{m}^{2} \mathrm{Ag} / 1 \mathrm{~mm}$ valve segment extension $(p=0.2)$, respectively. We also observed positive correlations between Mycoplasma pneumoniae and $\mathrm{CD}_{4} 5^{+}$cells $(r=0.51$ and $p=0.02)$ and MMP9 $(r=0.45$ and $p=0.04)$. The presence of Borrelia burgdorferi antigens was positively correlated with the percentage of $\mathrm{MD}$ ( $r=0.52$ and $p=0.018$ ). In previous studies, the presence of various symbiotic bacteria has been associated with the formation of tissue injury. In the aortic valve, Chlamydophila pneumoniae and Mycoplasma pneumoniae proliferation was associated with tissue calcification and aortic valve stenosis [16, 17]. Roggerio et al. studied the relationship between Mycoplasma pneumoniae and Chlamydophila pneumoniae in aortic aneurysms and identified these bacteria in the adventitia of the aorta, concluding that infectious agents, acting symbiotically, can contribute to the development of aortic aneurysms, initiating inflammation and contributing to the disease process [18].

Both groups had an average age of approximately 67 years. The valve impairment in the control group can be explained by age-related progressive degeneration of the extracellular matrix through the action of collagenolytic enzymes secreted by interstitial cells that cause abnormalities in collagen [19].

Infectious agents are often present in cardiovascular disease, with roles for these pathogens in its genesis or 


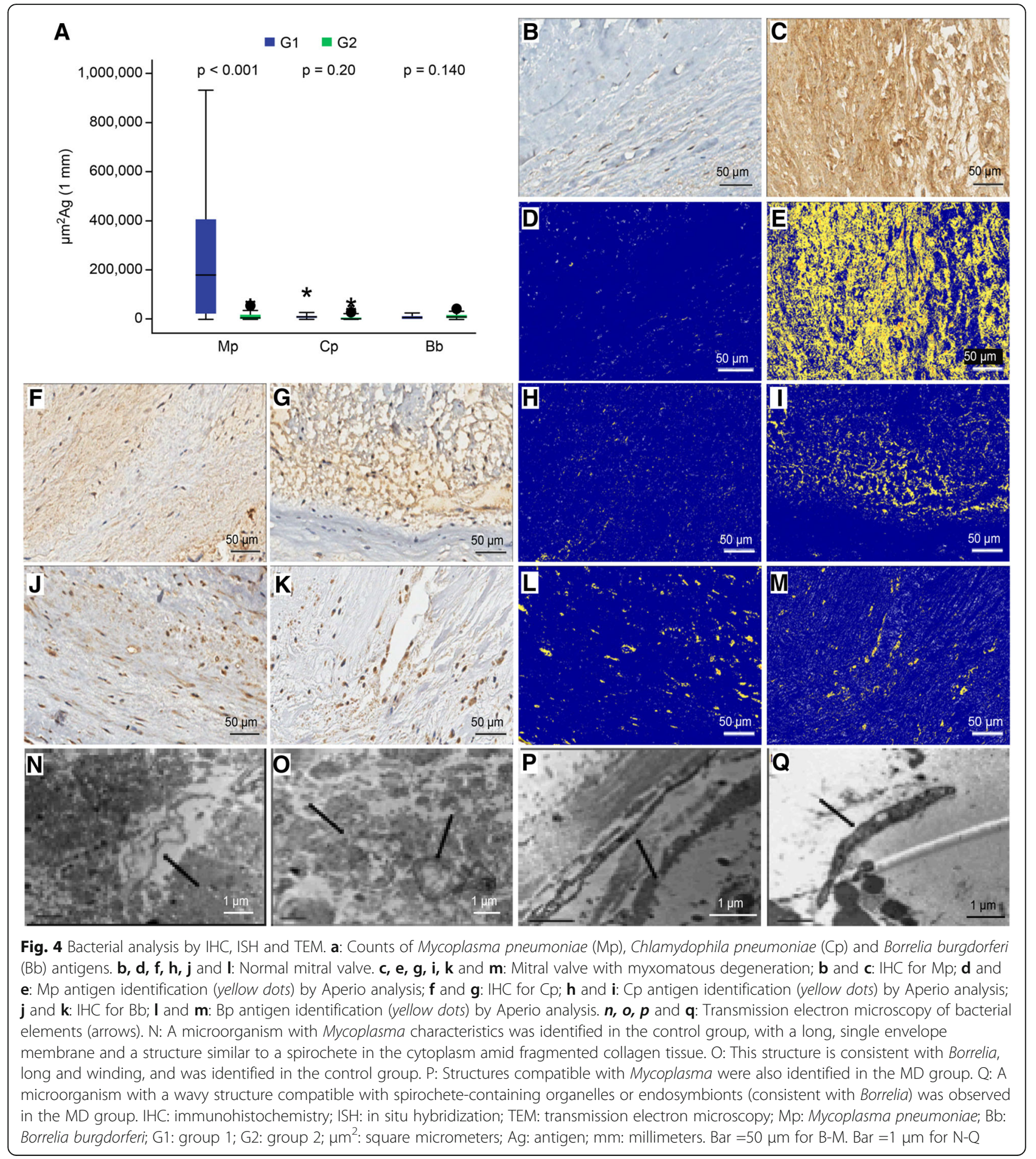

prior to its inception reported in several papers. Recently, Mangini et al. detected the presence of Mycoplasma pneumoniae, Chlamydophila pneumoniae and Borrelia burgdorferi in hearts with dilated cardiomyopathy, including Chagas disease [20]. In the aortic valve, the proliferation of Chlamydophila pneumoniae and Mycoplasma pneumoniae was related to tissue calcification and aortic valve stenosis [21]. Inflammatory cells and metalloproteinases have also been associated with the MD process. Veinot et al. analyzed five valves with MD and observed an increase in markers of mast cells (CD117), suggesting the participation of an inflammatory process triggered by myxoid degeneration. $\mathrm{CD}_{117^{+}}$cells are young cells identified in mitral valves that represent a degree of heart regeneration 


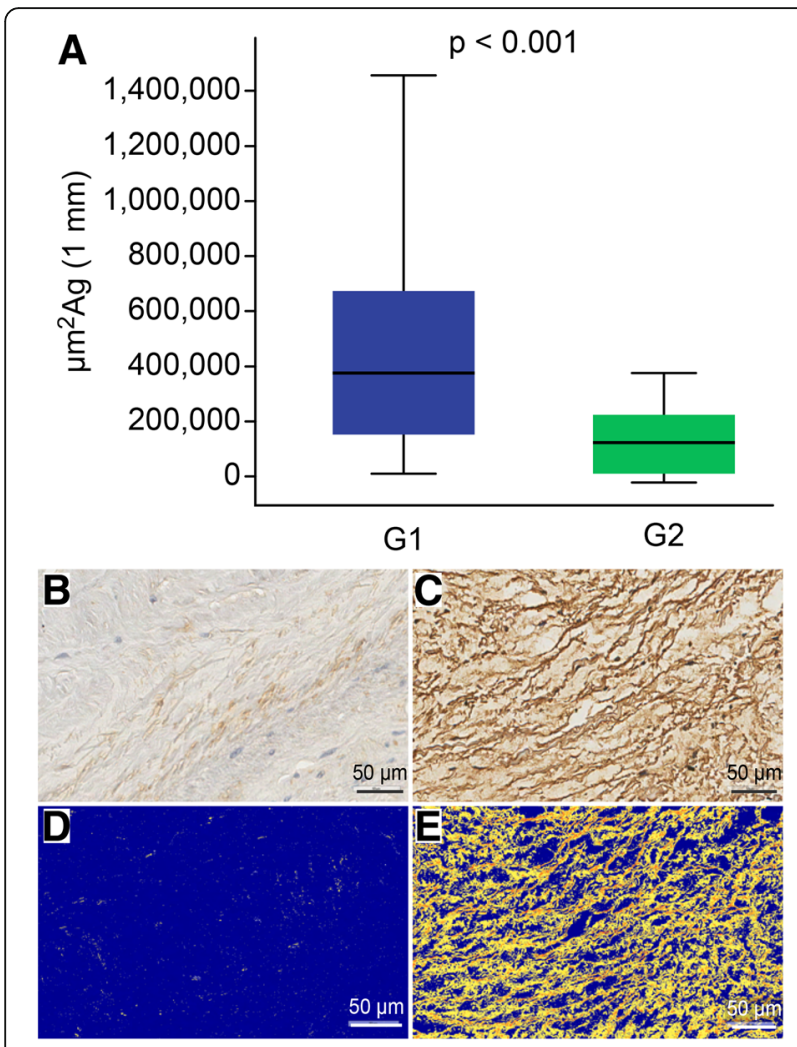

Fig. 5 MMP9 analysis. a: Counts of MMP9 antigens. $\mathbf{b}$ and $\mathbf{d}$ : Normal mitral valve. $\mathbf{c}$ and $\mathbf{e}$ : Mitral valve with myxomatous degeneration; $\mathbf{b}$ and c: IHC for MMP9; $\mathbf{d}$ and e: MMP9 antigen identification (yellow and orange dots) by Aperio analysis. IHC: immunohistochemistry; G1: group 1; G2: group 2; $\mu \mathrm{m}^{2}$ : square micrometers; Ag: antigen; mm: millimeters. Bar $=50 \mu \mathrm{m}$

capacity against stress, trauma or ischemia [3]. Barth et al. analyzed the presence of $\mathrm{CD} 34^{+}$fibrocytes in 15 myxoid valves and 10 valves without degeneration and found that these cells appear to be morphologically altered [7]. Rabkin et al. identified a role for MMP9, as well as other collagenases like MMP1, MMP2 and MMP13, in the breakdown of collagen in myxomatous degeneration [19]. The involvement of bacteria in the etiology of MVD has not previously been described. It is possible that the

Table 3 Correlations between bacterial antigens versus inflammatory cells versus MMP-9

\begin{tabular}{|c|c|c|c|c|}
\hline & \multicolumn{2}{|l|}{$\mathrm{MD}$} & \multicolumn{2}{|l|}{$\mathrm{CO}$} \\
\hline & $r$ & $p$ & $r$ & $p$ \\
\hline $\mathrm{Bb} \times \% \mathrm{MD}$ & 0.52 & 0.018 & 0.15 & 0.5 \\
\hline $\mathrm{CD} 45 \times \mathrm{Mp}$ & 0.51 & 0.02 & 0.01 & 0.9 \\
\hline Mp x MMP9 & 0.45 & 0.04 & 0.17 & 0.6 \\
\hline$M p \times \% M D$ & -0.34 & 0.13 & 0.04 & 0.8 \\
\hline MMP9 $\times \%$ MD & -0.02 & 0.91 & 0.4 & 0.07 \\
\hline
\end{tabular}

$M D$ myxomatous degeneration, $\mathrm{CO}$ control, Bb Borrelia burgdorferi, $\mathrm{Mp}$ Mycoplasma pneumoniae, MMP9 metalloproteinase 9. presence of such agents could lead to collagen degradation and increase local inflammation, facilitating the process of myxoid degeneration. This scenario warrants further investigation.

The presence of microorganisms as host symbionts is not well understood but is increasingly being studied. Scholars believe that microbial symbionts may fundamentally alter the host organism's physiology and sometimes impart new or optimized abilities that result in more adapted or healthier individuals [22]. When more than one microparasite species infects the same host, interactions between these parasites can exacerbate their symbiotic and immunological effects [23, 24]. In this study, the valves in the control group exhibited more Borrelia burgdorferi antigens than the valves in the MVD group. However, in the valves with MVD, the presence of Borrelia burgdorferi was associated with more myxomatous degeneration, and an interaction with Mycoplasma pneumoniae may have contributed to collagen degradation through a synergistic effect between these agents. Considering that we observed Mycoplasma pneumoniae and Borrelia burgdorferi in both groups but in different quantities and morphologies, these agents might also produce different responses with respect to collagen degradation. The presence of Mycoplasma pneumoniae can stimulate hyperactive macrophages, with subsequent cytotoxic $\mathrm{T}$ cell activation inducing fibroblast apoptosis [25]. In addition, the MVD group exhibited more Mycoplasma pneumonia, which positively correlated with gelatinase MMP9, an enzyme that participates in collagen degradation, as reported by other authors $[9,19]$. In our study, we also identified a greater number of $\mathrm{CD} 68^{+}$cells in the valve segments of the control group. Rabkin et al. associated the presence of macrophages in normal mitral valves with a minor amount of proteolytic enzymes [19]. Though valves with MD had fewer $\mathrm{CD}^{+} 8^{+}$cells, they still had higher quantities of B and $\mathrm{T}$ lymphocytes, including cytotoxic $\mathrm{T}$ lymphocytes that can release cytokines such as perforin and the granzina B leading to cell apoptosis and contributing to collagen degradation. It is possible that the $\mathrm{CD}^{+} 8^{+}$cells function as protective factors against collagen degradation.

Scholars have suggested that Borrelia burgdorferi strains interact competitively with the host [26]. In a recent study, Devevey et al. analyzed three different strains of Borrelia burgdorferi sensu strictu in 36 rats and detected a strong and competitive inhibitory interaction among the strains. In all cases, the strain that infected first exhibited a fitness advantage, mainly because colonization of the rat tissue by subsequent strains was inhibited. This inhibition is most likely due to the production of specific antibodies against Borrelia protein antigens [27]. The presence of bacteria and their relationships with collagen degradation as well as increased 
local inflammation can facilitate myxomatous degeneration, and the synergistic actions of multiple symbionts seem to be a contributing factor in MVD pathogenesis.

We are aware of the limitations of our study, especially the restrictions of the methodological design, including the sample size. Another limitation of this work is that the control group included cases with cardiovascular diseases such as myocardial infarction and aortic aneurysm, though these conditions did not appear to influence the results (Additional file 1). Moreover, in the control patients, we identified several degeneration foci with histological features consistent with MD, though they were not enough to lead to a breakdown in the valve structure. The results of this study will form a strong foundation for future research into the hypothesis that symbiotic actions of the bacteria play a key role in the development of myxoid degeneration of the mitral valve. More studies will be needed to confirm this causal relationship.

\section{Conclusion}

The presence of infectious agents, inflammatory cells and collagenases in mitral valves appear to contribute to the pathogenesis of MVD. Mycoplasma pneumoniae was strongly related with myxomatous mitral valve degeneration. Despite of low percentage of Borrelia burgdorferi in MD group, this agent was correlated with myxomatous degeneration and this may occour due synergistic actions between this infectious agents likely contribute to collagen degradation.

\section{Additional file}

Additional file 1: Quantification of antigens of Borrelia burgdorferi, Mycoplasma pneumoniae and MMP 9 containing only the cases with cardiovascular disease associated. (DOCX $15 \mathrm{~kb}$ )

\section{Abbreviations}

Bb: Borrelia burgdorferi; CO: Control; Cp: Chlamydophila pneumoniae; IHC: Immunohistochemistry; ISH: In situ hybridization; MD: Myxomatous degeneration; MMP9: Metalloproteinase 9; Mp: Mycoplasma pneumoniae; MVD: Mitral valve degeneration; MVP: Mitral valve prolapse;

TEM: Transmission electron microscopy

\section{Acknowledgements}

We thank Creusa Dal Bó for statistical review.

\section{Funding}

The funding for this study was provided by FAPESP (Support Foundation of São Paulo Research) by protocol number 2014/04383-4.

\section{Availability of data and materials}

All relevant data are available in the tables and figures. The raw data supporting our findings can be found by contact with autor across e-mail (mgtiveron@yahoo.com.br).

\section{Authors' contribution}

MGT are responsible conducted the experiment, the data collection and data analysis assistance of MMR. PMAP and MLH are responsible for the design and conception of the experiment and interpretation of final results.
Reviewed, revised, and edited the final manuscript. JK and RI conducted the immunohistochemistry and in situ hybridization experiment. JJP conducted the transmission electron microscopy experiment and analysis. MMR conducted the data analysis and interpretation. CMAB reviewed, revised, and edited the final manuscript. FBJ reviewed and revised the manuscript. All authors contributed to the final manuscript. All authors read and approved the final manuscript.

\section{Authors' information}

All the authors are from Heart Institute (InCor), School of Medicine of University of Sao Paulo.Marcos Gradim Tiveron is Cardiac Surgeon and Fellow of Department of Heart Valve Surgery.Pablo Maria Alberto Pomerantzeff is cardiac surgeon specialized in valve diseases and is the director of the Surgical Unit of Valve Cardiopathy. Maria de Lourdes Higuchi is a pathologist expert in electron microscopy, director of the Laboratory of Cardiac Pathology, where the project was developed.Márcia Martins Reis is biologists specialized in cardiac diseases, expert in

immunohistochemestry.Jaqueline de Jesus Pereira is a Ms. student in Physiopathology.Joyce Kawakami is Biomedical technician in Cardiac Pathology Laboratory.Renata Ikegami is Biologist in Cardiac Pathology. Carlos Manuel de Almeida Brandão is Cardiac Surgeon specialized in valve diseases.Fabio Biscegli Jatene is a Cardiac Surgeon and Head Professor in the Program in Thoracic and Cardiovascular Surgery.

\section{Competing interests}

The authors declare that they have no competing interests.

\section{Consent for publication}

Not applicable".

\section{Ethics approval and consent to participate}

The Bioethics Committee of the Clinical Hospital of Medical School of the University of Sao Paulo approved the study, approval no. 0029/04. A written informed consent was taken from all participants. Written consent for participating in the study and consent to publish was obtained from each participant prior to the tests.

\section{Publisher's Note}

Springer Nature remains neutral with regard to jurisdictional claims in published maps and institutional affiliations.

\section{Author details}

${ }^{1}$ Program in Thoracic and Cardiovascular Surgery, Medical School, University of Sao Paulo, Av. Dr. Enéas de Carvalho Aguiar, 44, Sao Paulo 05403-900, Sao Paulo, Brazil. ${ }^{2}$ Heart Institute of the Clinical Hospital, Medical School, University of Sao Paulo, Sao Paulo, Brazil.

Received: 1 July 2016 Accepted: 6 April 2017

Published online: 21 April 2017

References

1. Criley JM, Lewis KB, Humphries JO, Ross RS. Prolapse of the mitral valve: clinical and cine-angiocardiographic findings. Br Heart J. 1966;28:488-96.

2. Grande-Allen KJ, Griffin BP, Ratliff NB, Cosgrove DM, Vesely I. Glycosaminoglycan profiles of myxomatous mitral leaflets and chordae parallel the severity of mechanical alterations. J Am Coll Cardiol. 2003;42:271-7.

3. Veinot JP, Prichett-Pejic W, Song J, et al. CD117-positive cells and mast cells in adult human cardiac valves - observations and implications for the creation of bioengineered grafts. Cardiovasc Pathol. 2006;15:36-40.

4. Freed LA, Levy D, Levine RA, et al. Prevalence and clinical outcome of mitral-valve prolapse. N Engl J Med. 1999;341:1-7.

5. Hayek E, Gring CN, Griffin BP. Mitral valve prolapse. Lancet. 2005;365:507-18

6. Movahed MR, Hepner AD. Mitral valvar prolapse is significantly associated with low body mass index in addition to mitral and tricuspid regurgitation. Cardiol Young. 2007;17:172-4.

7. Barth PJ, Koster H, Moosdorf R. CD34 fibrocytes in normal mitral valves and myxomatous mitral valve degeneration. Pathol Res Pract. 2005;201:301-4.

8. Hu X, Zhao Q. Autonomic dysregulation as a novel underlying cause of mitral valve prolapse: a hypothesis. Med Sci Monit. 2011;17:27-31.

9. Mahimkar R, Nguyen A, Mann M, et al. Cardiac transgenic matrix metalloproteinase-2 expression induces myxomatous valve 
degeneration: a potential model of mitral valve prolapse disease. Cardiovasc Pathol. 2009;18:253-61.

10. David TE, Armstrong S, McCrindle BW, Manlhiot C. Late outcomes of mitral valve repair for mitral regurgitation due to degenerative disease. Circulation. 2013;127:1485-92.

11. Higuchi ML, Reis MM, Sambiase NV, et al. Coinfection with Mycoplasma pneumoniae and Chlamydia pneumoniae in ruptured plaques associated with acute myocardial infarction. Arq Bras Cardiol. 2003;81:12-22.

12. Higuchi ML, Santos MH, Roggério A, Kawakami JT, Bezerra HG, Canzian M. A role for archaeal organisms in development of atherosclerotic vulnerable plaques and myxoid matrices. Clinics. 2006;61:473-8.

13. Krause PJ, Bockenstedt LK. Lyme disease and the heart. Circulation. 2013; 127:e451-4.

14. Berghoff W. Chronic Lyme disease and co-infections: differential diagnosis. Open Neurol J. 2012;6:158-78.

15. Muresian H. The clinical anatomy of the mitral valve. Clin Anat. 2009;22:85-98

16. Nystrom-Rosander C, Thelin S, Hjelm E, et al. High incidence of Chlamydia pneumoniae in sclerotic heart valves of patients undergoing aortic valve replacement. Scand J Infect Dis. 1997;29:361-5.

17. Higuchi-Dos-Santos MH, Pierri H, Higuchi ML, et al. Chlamydia pneumoniae and Mycoplasma pneumoniae in calcified nodes of stenosed aortic valves. Arq Bras Cardiol. 2005;84:443-8.

18. Roggério A, Sambiase NV, Palomino SAP, et al. Correlation of bacterial coinfection versus matrix metalloproteinase 9 and tissue inhibitor of metalloproteinase 1 expression in aortic aneurysm and atherosclerosis. Ann Vasc Surg. 2013;27:964-71.

19. Rabkin E, Aikawa M, Stone JR, Fukumoto Y, Libby P, Schoen FJ. Activated interstitial myofibroblasts express catabolic enzymes and mediate matrix remodeling in myxomatous heart valves. Circulation. 2001;104:2525-32.

20. Mangini S, Higuchi ML, Kawakami JT, et al. Infectious agents and inflammation in donated hearts and dilated cardiomyopathies related to cardiovascular diseases, Chagas' heart disease, primary and secondary dilated cardiomyopathies. Int J Cardiol. 2015;178:55-62.

21. Pierri H, Higuchi-Dos-Santos MH, Ml H, et al. Density of Chlamydia pneumoniae is increased in fibrotic and calcified areas of degenerative aortic stenosis. Int J Cardiol. 2006;108:43-7.

22. Hussa EA, Goodrich-Blair H. It takes a village: ecological and fitness impacts of multipartite mutualism. Annu Rev Microbiol. 2013;67:161-78.

23. Mideo N. Parasite adaptations to within-host competition. Trends Parasitol. 2009;25:261-8

24. Alizon S, van Baalen M. Multiple infections, immune dynamics, and the evolution of virulence. Am Nat. 2008;172:E150-68.

25. Muhlradt PF. Immunomodulation by mycoplasmas: artifacts, facts and active molecules. In: Razin S, Herrmann R, editors. Molecular biology and pathogenicity of mycoplasma. New York: Kluwer Academic/Plenum Publishers; 2002. p. 449.

26. Pedersen $A B$, Fenton $A$. Emphasizing the ecology in parasite community ecology. Trends Ecol Evol. 2007;22:133-9.

27. Devevey G, Dang T, Graves CJ, Murray S, Brisson D. First arrived takes all: inhibitory priority effects dominate competition between co-infecting Borrelia burgdorferi strains. BMC Microbiol. 2015;15:61.

\section{Submit your next manuscript to BioMed Central and we will help you at every step:}

- We accept pre-submission inquiries

- Our selector tool helps you to find the most relevant journal

- We provide round the clock customer support

- Convenient online submission

- Thorough peer review

- Inclusion in PubMed and all major indexing services

- Maximum visibility for your research

Submit your manuscript at www.biomedcentral.com/submit
Biomed Central 